\title{
Methane and Water Phase Equilibria in the Presence of Single and Mixed Electrolyte Solutions Using the Cubic-Plus-Association Equation of State
}

\author{
H. Haghighi, A. Chapoy and B. Tohidi \\ Centre for Gas Hydrate Research, Institute of Petroleum Engineering, Heriot-Watt University, Edinburgh EH14 4AS, Scotland - UK \\ e-mail: hooman.haghighi@pet.hw.ac.uk - antonin.chapoy@pet.hw.ac.uk - bahman.tohidi@pet.hw.ac.uk
}

\begin{abstract}
Résumé - Application de l'équation d'état Cubic-Plus-Association pour la prédiction des équilibres entre phases pour les systèmes contenant du méthane et de l'eau en présence d'électrolyte(s) - Les hydrates de méthane ont été largement présentés comme une potentielle nouvelle source d'énergie. Les hydrates à l'état naturel peuvent se former dans diverses roches ou sédiments si les conditions appropriées de pression et température en présence d'eau et de méthane sont réunies. Toutefois, la salinité des eaux de formation peut connaître d'importantes variations, et ces changements modifient la zone de stabilité des hydrates. En outre, l'eau de gisement produite avec les fluides de réservoir peut contenir diverses quantités de sels, pouvant prévenir la formation d'hydrates. Par conséquent, il est essentiel d'obtenir une meilleure compréhension de l'effet des sels sur la stabilité des hydrates. Dans cette communication, de nouvelles données expérimentales de dissociation d'hydrates de méthane en présence de solutions aqueuses contenant différentes concentrations de $\mathrm{NaCl}, \mathrm{KCl}$ et de $\mathrm{MgCl}_{2}$ ont été réalisées. Les nouvelles données ont été mesurées en utilisant une méthode à volume constant. La précision et la fiabilité des mesures expérimentales ont été démontrées en comparant les mesures avec les données de la littérature. Une approche thermodynamique dans lequel l'équation d'état CPA est combinée avec une modification du terme électrostatique proposé par Debye-Hückel a été employée pour modéliser les équilibres entre phases. Les conditions de formation d'hydrates sont modélisées par la théorie développée par van der Waals et Platteeuw. Pour modéliser en milieux poreux les équilibres entre phases d'hydrate, l'effet de la pression capillaire a été pris en compte. Les prédictions du modèle développé ont été validées par rapport à des données expérimentales indépendantes et les données obtenues dans ce travail. Un bon accord entre les prédictions et les données expérimentales a été observé, confirmant la fiabilité du modèle développé.
\end{abstract}

\footnotetext{
Abstract - Methane and Water Phase Equilibria in the Presence of Single and Mixed Electrolyte Solutions Using the Cubic-Plus-Association Equation of State - Methane gas hydrates have been widely touted as a potential new source of energy. Methane hydrate has been found to form in various rocks or sediments given suitable pressures, temperatures, and supplies of water and methane. However, natural subsurface environments exhibit significant variations in formation water chemistry, and these changes create local shifts in the phase boundary. Furthermore, formation water produced with reservoir fluids contains various quantities of salts, which inhibit hydrate formation. Therefore, it is essential to gain a better understanding of the effect of aqueous electrolyte solutions on gas hydrate stability conditions. In this communication, we report new experimental dissociation data for methane simple hydrates in presence of aqueous solutions containing different concentrations of $\mathrm{NaCl}, \mathrm{KCl}$ and
} 


\begin{abstract}
$\mathrm{MgCl}_{2}$. The new data were generated by a reliable fixed-volume, isochoric, step-heating technique. The accuracy and reliability of the experimental measurements are demonstrated by comparing measurements with the literature data. A thermodynamic approach in which the Cubic-Plus-Association Equation of State is combined with a modified Debye Hïckel electrostatic term is employed to model the phase equilibria. The hydrate-forming conditions are modeled by the solid solution theory of van der Waals and Platteeuw. To model hydrate phase equilibria in porous media, the effect of capillary pressure has been taken into account. Predictions of the developed model are validated against independent experimental data and the data generated in this work. A good agreement between predictions and experimental data is observed, supporting the reliability of the developed model.
\end{abstract}

\section{INTRODUCTION}

Clathrate hydrates pertain to the class of clathrates formed through combination of water and suitably sized "guest" molecules under low temperature and elevated pressure conditions. Within the clathrate lattice, water molecules form a network of hydrogen-bonded cage-like structures that enclose the "guest" molecules - the latter comprising of single or mixed low-molecular diameter gases (e.g. methane) and organic compounds (Sloan, 1998). The stability of the clathrate hydrates, which have an ice-like appearance, is so substantial that they can exist at temperatures appreciably higher than triple point of $\mathrm{H}_{2} \mathrm{O}\left(T_{0}=273.16 \mathrm{~K}\right)$.

It is well recognized that very large quantities of methane hydrates occur naturally in sediments and therefore global interest in gas hydrates has grown steadily. However, the knowledge of the occurrence of in-situ gas hydrate is very incomplete, and is obtained from both indirect and direct evidence, methane hydrate deposits worldwide in permafrost regions and subsea sediments off continental margins is estimated to be two orders of magnitude greater than recoverable conventional gas resources (Sloan, 1998). Important issues driving research include the potential for methane hydrates as a strategic energy resource, increasing awareness of the relationship between hydrates and seafloor slope stability, the potential hazard hydrates pose to deepwater drilling installations, pipelines and subsea cables, and long-term considerations with respect to hydrate stability, methane (a potent greenhouse gas) release, and global climate change.

As one step towards a better understanding of the occurrence of gas hydrate in nature, the effects of salts and capillary pressure in porous media on phase equilibria as well as the boundary of hydrate formation must be known. Accurate knowledge of the thermodynamic stability of hydrates as a function of concentrations of salt is also crucial to the success of any flow assurance strategy. Thus, there has been a strong interest in developing either predictive thermodynamic models or correlations capable of predicting hydrate phase boundaries in systems containing single and mixed electrolytes.

In this work, the locus of the incipient hydrate-liquid water-vapor $\left(\mathrm{H}-\mathrm{L}_{\mathrm{W}}-\mathrm{V}\right)$ curve for ternary systems of methane and water with salts such as sodium chloride, magnesium chloride and potassium chloride in a wide range of concentrations and pressures are reported. These data in addition to the most reliable data from literature have been used to validate the predictive capabilities of a thermodynamic model.

A thermodynamic model based on the equality of fugacities of each component throughout all phases is employed to model the phase equilibria. For systems containing a component, which can form hydrogen bond (e.g., water), the CubicPlus-Association Equation of State (CPA-EoS) has been employed. The Binary Interaction Parameters (BIPs) between methane and water have been tuned using reliable gas solubility data and quadratic temperature dependent BIPs have been established. The CPA-EoS has been extended to predict fluid phase equilibria in the presence of single or mixed electrolyte solutions over a wide range of operational conditions. The hydrate-forming conditions are modeled by the solid solution theory of van der Waals and Platteeuw. Langmuir constants have been calculated using the Kihara potential model. The performance of the model has been tested by comparing the predictions with the data generated in this laboratory as well as the most reliable data from the open literature for hydrate stability zone (in bulk and porous media).

\section{REVIEW OF EXPERIMENTAL DATA}

\subsection{Methane Solubility in Water and Electrolyte Solutions}

The solubility of methane in pure water and aqueous electrolyte solutions has been measured over a wide pressure and temperature range by many researchers. The measurements of $\mathrm{CH}_{4}$ solubility in water and water content in gas phase are extensive. The sources of the experimental data for binary mixture of methane and water are given in Table 1.

Experimental methane solubility data in aqueous electrolyte solutions are not as extensive as water and solubility data in aqueous solutions with salts other than $\mathrm{NaCl}$ are rather limited. Table 2 shows the references for the reported measurements of $\mathrm{CH}_{4}$ solubility in saline water in the open literature. 
TABLE 1

Solubility data for methane in pure water binary systems

\begin{tabular}{|c|c|c|c|c|c|}
\hline References & $T(\mathrm{~K})$ & $P(\mathrm{MPa})$ & References & $T(\mathrm{~K})$ & $P(\mathrm{MPa})$ \\
\hline Frolich et al. (1931) & 298.15 & $3-12$ & Price (1979) & 427.15-627.15 & $3.54-197.20$ \\
\hline Michels et al. (1936) & $298.15-423.15$ & $4.06-46.91$ & Stoessel and Byrne (1982) & 298.15 & $2.41-5.17$ \\
\hline Culberson et al. (1950) & 298.15 & $3.62-66.74$ & Crovetto et al. (1982) & $297.5-518.3$ & $1.9-6.4$ \\
\hline Culberson and Mc Ketta (1951) & $298.15-444.26$ & $2.23-68.91$ & Cramer (1984) & $277.15-573.15$ & $3-13.2$ \\
\hline Morrison and Billet (1952) & 285.05-348.35 & $0.1(\mathrm{~atm})$ & Yarym-Agaev et al.(1985) & $313.15-338.15$ & $2.5-12.5$ \\
\hline Davis and McKetta (1960) & $310.93-394.26$ & $0.35-3.84$ & Yokoyama et al. (1988) & $298.15-323.15$ & $3-8$ \\
\hline Duffy et al. (1961) & 298.15-303.15 & $0.32-5.17$ & Abdulgatov et al. (1993) & $523.15-653.15$ & $2-64$ \\
\hline McAuliffe (1963) & 298.15 & $0.1(\mathrm{~atm})$ & Wang et al. (1995) & $283.15-298.15$ & $1.15-5.18$ \\
\hline Pierotti (1965) & 298.15 & $0.1(\mathrm{~atm})$ & Reichl (1996) & $283.16-343.16$ & $0.18-0.26$ \\
\hline Hilderbrabd (1968) & 298.15 & $0.1(\mathrm{~atm})$ & Lekvam and Bishnoi (1997) & 274.19-285.68 & $0.57-9.08$ \\
\hline O’Sullivan and Smith (1970) & $324.65-398.15$ & $10.13-61.61$ & Song et al. (1997) & $273.15-288.15$ & 3.45 \\
\hline Sultanov et al. (1971) & $423.15-633.15$ & $4.90-107.87$ & Yang et al. (2001) & $298.1-298.2$ & $2.33-12.68$ \\
\hline Amirijafari and Campbell (1972) & $310.93-344.26$ & 4.13-34.46 & Servio and Englezos (2002) & $278.65-284.35$ & $3.5-6.5$ \\
\hline Maharajh and Walkley (1973) & 298.15 & $0.1(\mathrm{~atm})$ & Kim et al. (2003) & 298.15 & $2.3-16.6$ \\
\hline Tokunaga and Kawai (1975) & 293.15 & $0.1(\mathrm{~atm})$ & Wang et al. (2003) & $283.2-303.2$ & $2-40.03$ \\
\hline Sanchez and De Meer (1978) & $423.15-573.15$ & $10-250$ & Chapoy et al. (2004) & 275.11-313.11 & $0.97-18.0$ \\
\hline
\end{tabular}

TABLE 2

Methane solubility in various aqueous electrolyte solutions

\begin{tabular}{|c|c|c|c|}
\hline References & Solutions & $T(\mathrm{~K})$ & $P(\mathrm{MPa})$ \\
\hline \multirow[t]{2}{*}{ Michels et al. (1936) } & $5.52-27.8$ mass $\% \mathrm{NaCl}$ & $298.15-423.15$ & $4.18-45.61$ \\
\hline & 24.41-2.54 mass $\% \mathrm{CaCl}_{2}$ & 298.15 & $5.62-21.0$ \\
\hline Eucken and Hertzberg (1950) & $0-14$ mass $\% \mathrm{NaCl}$ & $273.15-293.15$ & 0.1 (atm) \\
\hline \multirow[t]{3}{*}{ Duffy et al. (1961) } & 2.84-26.3 mass $\% \mathrm{NaCl}$ & 303.15 & $21.48-95.75$ \\
\hline & $0-45$ mass $\% \mathrm{CaCl}_{2}$ & $298.15-303.15$ & $0.32-7.48$ \\
\hline & $\mathrm{NaCl}+\mathrm{CaCl}_{2}$ & 303.15 & $0.32-5.19$ \\
\hline Mishnina et al. (1962) & $0-26.7$ mass $\% \mathrm{NaCl}$ & $277.15-363.15$ & $0.1(\mathrm{~atm})$ \\
\hline O’Sullivan and Smith (1970) & $5.57-20.5$ mass $\% \mathrm{NaCl}$ & $324.65-398.15$ & $10.13-61.61$ \\
\hline Ben-Naim and Yaacobi (1974) & $0-11$ mass $\% \mathrm{NaCl}$ & $283.15-303.15$ & $0.1(\mathrm{~atm})$ \\
\hline Yano et al. (1974) & $0-8.31$ mass $\% \mathrm{NaCl}$ & 298.15 & $0.1(\mathrm{~atm})$ \\
\hline Blanco and Smith (1978) & 10 mass $\% \mathrm{CaCl}_{2}$ & $298.2-398.2$ & $10.1-60.8$ \\
\hline Namiot et al. (1979) & $0-8.3$ mass $\% \mathrm{NaCl}$ & $323-623$ & 29.5 \\
\hline Blount and Price (1982) & $0-25.6$ mass $\% \mathrm{NaCl}$ & $372.15-513.15$ & $7.5-157$ \\
\hline \multirow[t]{4}{*}{ Stoessell and Byrne (1982) } & $0-19$ mass $\% \mathrm{NaCl}$ & 298.15 & $2.41-5.17$ \\
\hline & $0-30.75$ mass $\% \mathrm{KCl}$ & 298.15 & $2.41-5.17$ \\
\hline & $0-17$ mass $\% \mathrm{MgCl}_{2}$ & 298.15 & $2.41-5.17$ \\
\hline & 0-18.17 mass $\% \mathrm{CaCl}_{2}$ & 298.15 & $2.41-5.17$ \\
\hline Cramer (1984) & $4.52-21.55$ mass $\% \mathrm{NaCl}$ & $273.7-574.3$ & $1.9-12.4$ \\
\hline Krader and Franck (1987) & $0-10.5$ mass $\% \mathrm{NaCl}$ & $638-799$ & $40-263$ \\
\hline Kiepe et al. (2003) & $7-23$ mass $\% \mathrm{KCl}$ & 313.51-373.19 & $0.42-9.79$ \\
\hline
\end{tabular}




\subsection{Phase Equilibria for Methane Hydrates in the Presence of Electrolyte Solutions}

Most of the experimental works have been focused on hydrate dissociation pressures or temperatures in pure water system. Experimental studies on hydrate dissociation for systems containing salts have been less investigated; only a few authors have presented experimental results for hydrate inhibition. The presence of a salt moves the conditions required for gas hydrate formation to lower temperatures and (or) higher pressures. Tables 3 and 4 list some of the available experimental data sets for methane hydrate dissociation condition in the presence of $\mathrm{NaCl}, \mathrm{CaCl}_{2}, \mathrm{MgCl}_{2}$ and different mixtures of $\mathrm{NaCl}$ and $\mathrm{KCl}$, respectively.

\section{NEW EXPERIMENTAL DATA FOR METHANE HYDRATES IN PRESENCE OF ELECTROLYTE SOLUTIONS}

\subsection{Materials}

Aqueous solutions of different salts used in this work were prepared gravimetrically in this laboratory. All the salts used were of analytical reagent grade and with reported purities of
$>99 \%$ for anhydrous $\mathrm{NaCl}$ (Aldrich) and $\mathrm{KCl}$ (Aldrich). Hexahydrate $\mathrm{MgCl}_{2}$ (Aldrich) with reported purities of $>98 \%$ was also used without further purification. Solutions were prepared using deionized water throughout the experimental work.

\subsection{Apparatus and Experimental Procedures}

Figure 1 shows the apparatus used to determine the phase equilibrium conditions. The phase equilibrium is achieved in a cylindrical cell made of stainless steel. The cell volume is about $500 \mathrm{~mL}$ and it can be operated up to $40 \mathrm{MPa}$ between $243 \mathrm{~K}$ and $323 \mathrm{~K}$. The equilibrium cell is held in a metallic jacket heated or cooled by a constant temperature liquid bath. The temperature of the cell is controlled by circulating coolant from a cryostat within the jacket surrounding the cell. The cryostat is capable of maintaining the cell temperature to within $0.1 \mathrm{~K}$. To achieve good temperature stability, the jacket is insulated with polystyrene board and the pipes (which connect it to the cryostat) are covered with plastic foam. A platinum resistance probe monitors the temperature and is connected directly to a computer for direct acquisition. The pressure is measured by means of a strain gauge pressure

TABLE 3

Methane hydrate dissociation data in presence of aqueous $\mathrm{NaCl}, \mathrm{MgCl}_{2}$ and $\mathrm{CaCl}_{2}$ electrolyte solutions

\begin{tabular}{|c|c|c|c|c|}
\hline Salt & References & WS (mass \%) & $T(\mathrm{~K})$ & $P(\mathrm{MPa})$ \\
\hline \multirow[t]{6}{*}{$\mathrm{NaCl}$} & Kobayashi et al.(1951) & 10 and 20 & $265.9-284.3$ & $2.59-13.66$ \\
\hline & De Roo et al. (1983) & $11.7,17.1,21.5$ and 24.1 & $261.85-278.05$ & $2.39-11$ \\
\hline & Maekawa et al.(1995) & $3.5,10$ and 20 & $268.6-288.9$ & $3-18.2$ \\
\hline & Maekawa and Imai (1999) & 10 and 20 & $262.5-283$ & $3.01-12.26$ \\
\hline & Jager and Sloan (2001) & $6.2,10.8,17.1$ and 22 & $270.66-299.06$ & $6.6-71.56$ \\
\hline & Kharrat and Dalmazzone (2003) & 11.9 and 17.1 & $269.2-277.7$ & $4.23-8.57$ \\
\hline \multirow[t]{2}{*}{$\mathrm{MgCl}_{2}$} & Kang et al. (1998) & $3,6,10$ and 15 & $270.75-286.4$ & $2.82-12.95$ \\
\hline & Atik et al. (2006) & $1,5,10$ and 15 & 270.4-292.2 & $3.46-22.65$ \\
\hline \multirow[t]{2}{*}{$\mathrm{CaCl}_{2}$} & Kharrat and Dalmazzone (2003) & $5,10,15,20,23$ and 26 & 259.9-284.4 & $4.92-10.29$ \\
\hline & Atik et al. (2006) & 17 & $265.4-282.2$ & $3.03-22.93$ \\
\hline
\end{tabular}

TABLE 4

Methane hydrate dissociation data in the presence of mixed $\mathrm{NaCl}$ and $\mathrm{KCl}$ electrolyte solutions

\begin{tabular}{|c|c|c|c|c|}
\hline Reference & Solution & Solution ID & $T(\mathrm{~K})$ & $P(\mathrm{MPa})$ \\
\hline \multirow[t]{6}{*}{ Dholabhai et al. (1991) } & 3 mass $\% \mathrm{NaCl}$ and 3 mass $\% \mathrm{KCl}$ & $\mathrm{Na} 3 \mathrm{~K} 3$ & $271.35-279.2$ & $2.704-5.857$ \\
\hline & 3 mass $\% \mathrm{NaCl}$ and 5 mass $\% \mathrm{KCl}$ & Na3K5 & $270.32-281.46$ & $2.829-9.379$ \\
\hline & 5 mass $\% \mathrm{NaCl}$ and 10 mass $\% \mathrm{KCl}$ & Na5K10 & $267.49-279$ & $2.569-9.046$ \\
\hline & 5 mass $\% \mathrm{NaCl}$ and 15 mass $\% \mathrm{KCl}$ & $\mathrm{Na} 5 \mathrm{~K} 15$ & 266.29-276.19 & $2.914-8.689$ \\
\hline & 10 mass $\% \mathrm{NaCl}$ and 12 mass $\% \mathrm{KCl}$ & $\mathrm{Na} 10 \mathrm{~K} 12$ & $264.58-274.23$ & $2.989-8.819$ \\
\hline & 15 mass $\% \mathrm{NaCl}$ and 8 mass $\% \mathrm{KCl}$ & $\mathrm{Na} 15 \mathrm{~K} 8$ & $264.38-272.12$ & $3.614-8.839$ \\
\hline
\end{tabular}




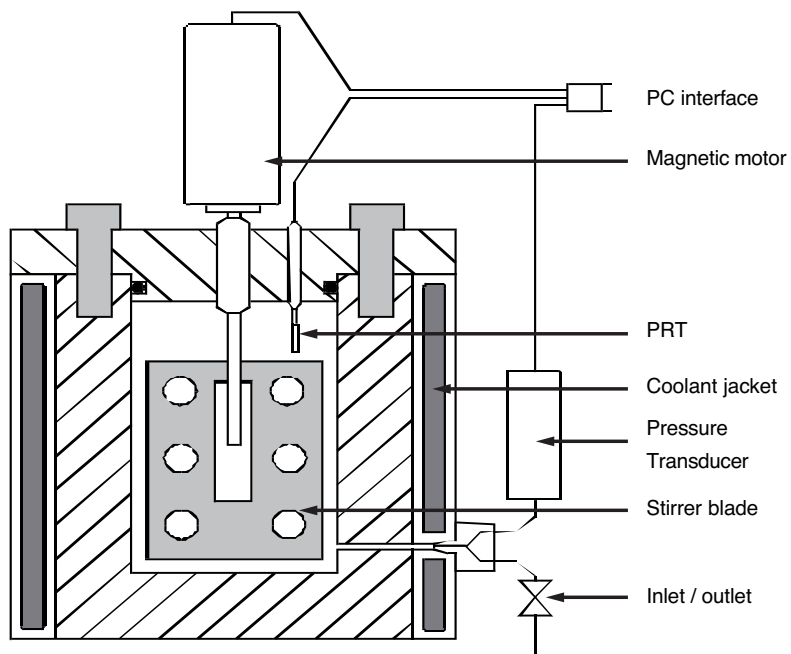

Figure 1

Schematic illustration of the experimental set-up.

transducer mounted directly on the cell and connected to the same data acquisition unit. This system allows real time readings and storage of temperatures and pressures throughout the different isothermal runs. To achieve a fast thermodynamic equilibrium and to provide a good mixing of the fluids, a stirrer with a magnetic motor was used to agitate the test fluids.

Prior to the tests the equilibrium cell was cleaned and evacuated. The aqueous solution of different salts was loaded into the cell and then methane gas was injected into the cell to achieve the desired starting pressure. Once the cell had been charged with the desired components the mixer was switched on and the temperature lowered to form hydrates, their presence being confirmed by pressure drop. The hydrate formation caused a rapid decline in the cell pressure as gas molecules were consumed during the process. The temperature was then increased stepwise, slowly enough to allow equilibrium to be achieved at each temperature step. At temperatures below the point of complete dissociation, gas is released from decomposing hydrates, giving a marked rise in the cell pressure with each temperature step (Fig. 2). However, once the cell temperature has passed the final hydrate dissociation point, and all clathrates have disappeared from the system, a further rise in the temperature will result only in a relatively small pressure rise due to thermal expansion. This process results in two traces with very different slopes on a pressure versus temperature $(P / T)$ plot; one before and one after the dissociation point. The point where these two traces intersect (i.e., an abrupt change in the slope of the $P / T$ plot) is taken as the dissociation point (see Fig. 2). Dissociation point measurements measured using this reliable isochoric step-heating method has been previ- ously demonstrated as being considerably more reliable and repeatable than conventional continuous heating and/or visual techniques (Tohidi et al., 2000). The procedure was repeated at different pressures in order to determine the hydrate phase boundaries over a wide temperature range. In this work, methane hydrate dissociation points were measured in the presence of aqueous solutions containing different concentrations of $\mathrm{NaCl}, \mathrm{KCl}$ and $\mathrm{MgCl}_{2}$ (Tab.5).

\section{THERMODYNAMIC MODELING}

For a system at equilibrium, from a thermodynamic view-point, the criterion for phase equilibrium is the equality of chemical potentials of each component in all coexisting phases. For an isothermal system this will reduce to the equality of fugacity of each component in different phases. The fugacity of each component in the salt-free water phase has been calculated by the well-proven Cubic-Plus-Association Equation of State (CPA-EoS) (Kontogeorgis et al., 2006). The CPA-EoS combines the well-known Soave-Redlich-Kwong (SRK) EoS for describing the physical interactions with the Wertheim's first-order perturbation theory, which can be applied to different types of hydrogen-bonding compounds. Water parameters (water is the only associating component here) in the CPA-EoS have been determined from pure liquid water properties by Kontogeorgis et al. (1999). When salt is present, the fugacity of non-electrolyte components in the aqueous

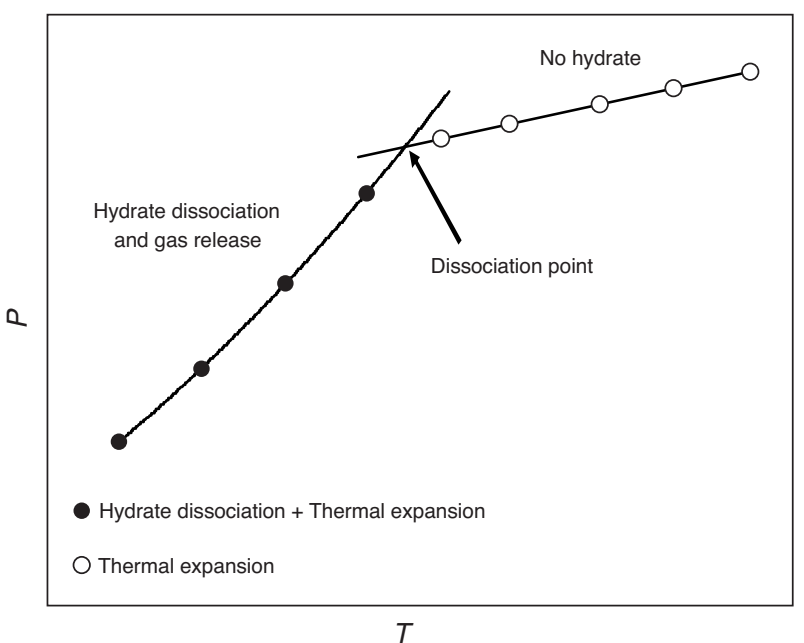

Figure 2

Dissociation point determination from equilibrium stepheating data. The equilibrium dissociation point is determined as being the intersection between the hydrate dissociation (pressure increase as a result of gas release due to temperature increase and hydrate dissociation, as well as thermal expansion) and the linear thermal expansion (no hydrate) curves. 
TABLE 5

Methane hydrate dissociation points in the presence of aqueous single electrolyte solutions (present work)

\begin{tabular}{c|c|c}
\hline Solution & $T(\mathrm{~K})$ & $P(\mathrm{MPa})$ \\
\hline \multirow{2}{*}{15 mass\% NaCl } & 269.45 & 3.93 \\
\cline { 2 - 3 } & 282.20 & 17.81 \\
\cline { 2 - 3 } & 285.05 & 26.50 \\
\hline \multirow{2}{*}{20 mass\% NaCl } & 268.55 & 5.02 \\
\cline { 2 - 3 } & 274.95 & 10.31 \\
\cline { 2 - 3 } & 277.25 & 15.38 \\
\hline \multirow{2}{*}{15 mass\% KCl } & 276.45 & 6.24 \\
\cline { 2 - 3 } & 281.10 & 10.89 \\
\cline { 2 - 3 } & 284.95 & 17.28 \\
\hline \multirow{2}{*}{10 mass\% $\mathrm{MgCl}_{2}$} & 274.28 & 4.32 \\
\cline { 2 - 3 } & 280.90 & 10.27 \\
\cline { 2 - 3 } & 284.05 & 15.00 \\
\cline { 2 - 3 } & 287.38 & 24.78 \\
\hline
\end{tabular}

phase are calculated by combining the EoS with the Debye Hückel electrostatic contribution term (AasbergPetersen et al., 1991). The hydrate-forming conditions are modeled by the solid solution theory of van der Waals and Platteeuw (1959). Langmuir constants have been calculated by using Kihara potential parameters tuned to methane hydrate dissociation data (Kihara, 1953).

\subsection{Modeling of Solubility of Methane in Water}

Species forming hydrogen bonds often exhibit unusual thermodynamic behavior due to strong attractive interactions between molecules of the same species (self-association) or between molecules of different species (cross-association). These interactions may strongly affect the thermodynamic properties of the fluids. Thus, the chemical equilibria between clusters should be taken into account in order to develop a reliable thermodynamic model. The Cubic-PlusAssociation (CPA) model, an Equation of State that combines the cubic SRK Equation of State and an association (chemical) term, is used in this work for fugacity calculations in phase equilibria calculations. The CPA EoS can be expressed for mixtures in terms of pressure $P$ (Kontogeorgis et al., 1999):

$$
\begin{aligned}
& P=\frac{R T}{V_{m}-b}-\frac{a(T)}{V_{m}\left(V_{m}+b\right)}-\frac{1}{2} \frac{R T}{V_{m}} \\
& +\left(1+\rho \frac{\partial \ln (g)}{\partial \rho}\right) \sum_{i} x_{i} \sum_{A_{i}}\left(1-X^{A_{i}}\right)
\end{aligned}
$$

where the physical term is that of the SRK EoS and the association term is taken from the SAFT EoS (Huang and
Radosz, 1990). $X^{A_{i}}$ is the mole fraction of molecule $i$ not bonded to the site A and $x_{i}$ is the mole fraction of the component $i . X^{A i}$ can be rigorously defined as:

$$
X^{A_{i}}=\left(1+\rho \sum_{j} \sum_{B_{j}} x_{j} X^{B_{j}} \Delta^{A_{i} B_{j}}\right)^{-1}
$$

where $\rho$ is the molar density of the fluid, $x_{j}$ is the mole fraction of substance $j, X^{A_{i}}$ is related to the association strength between site $A$ and site $B$ on the molecule, and $\Delta^{A_{i} B_{j}}$, the association strength, is the key quantity in the CPA EoS. Both $X^{A_{i}}$ and $\Delta^{A_{i} B j}$ depend on the structure of the molecule and the number and type of sites. The association strength between site $A$ on molecule $i$ and site $B$ on molecule $j$ is given by:

$$
\Delta^{A_{i} B_{j}}=g(d)^{\text {simp. }}\left[\exp \left(\frac{\varepsilon^{A B}}{R T}\right)-1\right] \beta^{A_{i} B_{j}} b
$$

where $g(d)^{\text {simp. }}$ is the simplified expression of the radial distribution function as suggested by Kontogeorgis et al. (1999), $b$ is the co-volume parameter from the cubic part of the model, $\beta$ and $\varepsilon$ are the association volume and energy parameters of CPA, respectively. The latter two could be obtained from spectroscopy data but are in most cases estimated along with the parameters of the physical term. The simplified expression of the radial distribution function is:

$$
g(d)^{\text {simp. }}=\frac{1}{1-1.9 \eta}
$$

where $\eta$ is the reduced fluid density given as:

$$
\eta=\frac{1}{4} b \rho=\frac{b}{4 V_{m}}
$$

The energy parameter of the CPA-EoS, $a(T)$, is defined using a Soave-type temperature dependency:

$$
a(T)=a_{0}\left(1+C_{1}\left(1-\sqrt{T_{r}}\right)\right)^{2}
$$

The co-volume parameter $b$ is assumed to be temperature independent, in agreement with most published equations of state.

When the CPA-EoS is used for mixtures, the SRK part requires the conventional van der Waals one-fluid mixing rules for $a(T)$ and $b$. The mixing and combining rules for $a(T)$ and $b$ are the classical van der Waals equations:

$$
\begin{aligned}
& a(T)=\sum_{i} \sum_{j} x_{i} x_{j} a_{i j} \\
& b=\sum_{i} \sum_{j} x_{i} x_{j} b_{i j}
\end{aligned}
$$


where the classical combination rules are used:

$$
\begin{aligned}
& a_{i j}=\left(1-k_{i j}\right) \sqrt{a_{i} a_{j}} \\
& b_{i j}=\frac{b_{i}+b_{j}}{2}
\end{aligned}
$$

For binary systems containing a self-associating (water) and a non-associating compound (methane), the binary interaction parameters $k_{i j}$ are the only adjustable parameters and thus no combining rules are required for the associating energy and volume.

The selection of the association scheme and the maximum number of association sites can be found for a compound by looking at the location of its constituting hydrogen atoms and lone pairs on acceptor atom (oxygen for water molecules). Huang and Radosz (1990) have classified eight different association schemes, which can be applied to different molecules depending on the number and type of associating sites. The four-site (4C) association scheme is used for highly hydrogen-bonded substances, such as water, which have two proton donors and two proton acceptors per molecule. The CPA EoS pure compound parameters, used for the fugacity calculations in this paper are listed in Table 6.

\section{TABLE 6}

The CPA EoS pure compound parameters for methane and water

\begin{tabular}{c|c|c|c|c|c|c}
\hline & $\begin{array}{c}B \\
(\mathrm{~L} / \mathrm{mol})\end{array}$ & $\begin{array}{c}a_{0} \\
\left(\mathrm{bar} \mathrm{L}^{2} \mathrm{~mol}^{-2}\right)\end{array}$ & $c_{l}$ & $\begin{array}{c}\varepsilon \\
\left(\mathrm{bar} \mathrm{L} \mathrm{mol}^{-1}\right)\end{array}$ & $\begin{array}{c}\beta \\
\left(\mathrm{x} 103^{3}\right)\end{array}$ & References \\
\hline methane & 0.0284 & 2.278 & 0.444 & & & $\begin{array}{c}\text { Voutsas } \\
\text { et al., 2000 }\end{array}$ \\
\hline water & 0.0145 & 1.2277 & 0.6736 & 166.55 & 69.2 & $\begin{array}{c}\text { Kontogeorgis } \\
\text { et al., 1999 }\end{array}$ \\
\hline
\end{tabular}

\subsection{Modeling of Electrolyte Solutions}

When salt is present, the fugacities of non-electrolyte components in the aqueous phase are calculated by combining an EoS with the Debye Hückel electrostatic term to take into account the effect of electrolyte (Aasberg-Petersen et al., 1991):

$$
\ln \phi_{i}=\ln \phi_{i}^{E o S}+\ln \gamma_{i}^{E L} \quad i=1,2, \ldots, n
$$

where $n$ is the number of non-electrolyte components, $\phi_{i}$ is the fugacity coefficient of non-electrolyte component $i$ in the aqueous solution, $\phi_{i}{ }^{E o S}$ is the fugacity coefficient of non-electrolyte component $i$ using an EoS, neglecting the electrostatic effect, and $\gamma_{i}^{E L}$ is the contribution of the electrostatic term. The Equation of State (short-range interactions) is employed to calculate the effect of non-ionic (molecular) species in the aqueous phase and a DebyeHückel electrostatic term (long-range interactions) is used to model the effect of salts on the fugacity coefficients of molecular species in the solution. Using the Debye Hückel activity model, the second term in Equation (9) can be calculated from (Aasberg-Petersen et al., 1991):

$$
\ln \gamma_{i}^{D H}=\frac{2 A M_{m} h_{i s}}{B^{3}} f\left(B I^{1 / 2}\right)
$$

where $M_{m}$ is the salt-free mixture molecular weight determined as a molar average, and $h_{i s}$ is the binary interaction parameter between the dissolved salt and a non-electrolyte component. A detailed description of the modeling of ice phase, electrolyte solution and tuned binary interaction parameter, $h_{i s}$, as a function of salt concentration and temperature for the CPA EoS can be found elsewhere (Haghighi et al., 2008).

The change in gas solubility due to the presence of salts has been taken into account using the method introduced by Tohidi-Kalorazi (1995) in which the gas-salt interaction parameters are expressed as functions of temperature and salt concentration.

\subsection{Modeling of Hydrate Phase}

The statistical thermodynamic model of van der Waals and Platteeuw (1959) provides a bridge between the microscopic properties of the clathrate hydrate structure and macroscopic thermodynamic properties, i.e., the phase behavior. The hydrate phase is modeled by using the solid solution theory of van der Waals and Platteeuw (1959), as implemented by Parrish and Prausnitz (1972). The Kihara model for spherical molecules is applied to calculate the potential functions for compounds forming the hydrate phase (Kihara, 1953). The fugacity of water in the hydrate phase is given by the following equation (Anderson and Prausnitz, 1986):

$$
f_{w}^{H}=f_{w}^{\beta} \exp \left(-\frac{\Delta \mu_{w}^{\beta-H}}{R T}\right)
$$

where superscripts $H$ and $\beta$ refer to hydrate and empty hydrate lattice, respectively and $\mu$ stands for chemical potential. $f_{w}^{\beta}$ is the fugacity of water in the empty hydrate lattice. $\Delta \mu_{w}^{\beta}-H$ is the chemical potential difference of water between the empty hydrate lattice, $\mu_{w}^{\beta}$, and the hydrate phase, $\mu_{w}^{H}$, which is obtained by the van der Waals and Platteeuw expression:

$$
\Delta \mu_{w}^{\beta-H}=\mu_{w}^{\beta}-\mu_{w}^{H}=R T \sum_{m}^{-} v_{m} \ln \left(1+\sum_{j} C_{m j} f_{j}\right)
$$

where $\bar{v}_{m}$ is the number of cavities of type $m$ per water molecule in the unit cell, $f_{j}$ is the fugacity of the gas component $j$. $C_{m j}$ is the Langmuir constant, which accounts for the gaswater interaction in the cavity. The Langmuir constants are temperature dependent functions that describe the potential interaction between the encaged guest molecule and the water molecules surrounding it. Numerical values for the Langmuir 
constant can be calculated by choosing a model for the guesthost interaction (van der Waals and Platteeuw, 1959):

$$
C_{m j}(T)=\frac{4 \pi}{k T} \int_{0}^{\infty} \exp \left(-\frac{w(r)}{k^{\prime} T}\right) r^{2} d r
$$

where $k$ is Boltzmann's constant. The function $w(r)$ is the spherically symmetric cell potential in the cavity, with $r$ measured from the centre, and depends on the intermolecular potential function chosen for describing the encaged gaswater interaction. In the present work, the Kihara potential function (Kihara, 1953) is used as described in McKoy and Sinanoglu (1963).

$$
\begin{array}{ll}
\Gamma(r)=\infty & r \leq 2 \alpha \\
\Gamma(r)=4 \varepsilon\left[\left(\frac{\sigma^{*}}{r-2 \alpha}\right)^{12}-\left(\frac{\sigma^{*}}{r-2 \alpha}\right)^{6}\right] & r>2 \alpha
\end{array}
$$

where $\Gamma(r)$ is the potential energy of interaction between two molecules when the distance between their centers is equal to $r . \varepsilon$ is the characteristic energy, $\alpha$ is the radius of the spherical molecular core and $\sigma^{*}=\sigma-2 \alpha$ where $\sigma$ is the collision diameter, i.e., the distance where $\Gamma=0$. The methane Kihara potential parameters, $\alpha, \sigma$ and $\varepsilon$ are taken from TohidiKalorazi (1995) (Tab. 7).

\section{TABLE 7}

Kihara Potential Parameters for methane water interactions from Tohidi-Kalorazi, 1995.

\begin{tabular}{l|c|c|c}
\multicolumn{4}{c}{$\alpha=$ collision diameter, $\varepsilon=$ depth of energy well, } \\
\hline & $\alpha(\AA)$ & $\sigma^{* a}(\AA)$ & $(\varepsilon / k)(\mathrm{K})$ \\
\hline Methane & 0.2950 & 3.2512 & 153.685 \\
\hline${ }^{a} \sigma^{*}=\sigma-2 \alpha$ &
\end{tabular}

Based on the chosen potential energy function, the spherically symmetric cell potential in the cavities (Equation (13)) needs to be derived. The fugacity of water in the empty hydrate lattice, $f_{w}^{\beta}$ in Equation (11), is given by:

$$
f_{w}^{\beta}=f_{w}^{I / L} \exp \left(\frac{\Delta \mu_{w}^{\beta-I / L}}{R T}\right)
$$

where $f_{w}^{I / L}$ is the fugacity of either pure ice or liquid water whichever is the stable phase and $\Delta u_{w}^{\beta-I / L}$ is the difference in the chemical potential between the empty hydrate lattice and pure liquid water. $\Delta u_{w}^{\beta-I / L}$ is given by the following equation:

$$
\begin{aligned}
& \frac{\Delta \mu_{w}^{\beta-I / L}}{R T}=\frac{\mu_{w}^{\beta}(T, P)}{R T}-\frac{\mu_{w}^{I / L}(T, P)}{R T} \\
& =\frac{\Delta \mu_{w}^{0}}{R T_{0}}-\int_{T_{0}}^{T} \frac{\Delta h_{w}^{\beta-I / L}}{R T^{2}} d T+\int_{P_{0}}^{P} \frac{\Delta v_{w}^{\beta-I / L}}{R T} d P
\end{aligned}
$$

where superscript " 0 " stands for the triple point of water and $h$ refers to molar enthalpy. $\mu_{w}^{\beta}$ and $\mu_{w}^{I / L}$ are the chemical potential of the empty hydrate lattice and of pure water in the ice $(I)$ or the liquid $(L)$ state, respectively. $\Delta \mu_{w}^{0}$ is the reference chemical potential difference between water in the empty hydrate lattice and pure water at the triple point temperature of water $\left(T_{0}\right) . \Delta h_{w}^{\beta-I / L}$ and $\Delta v_{w}^{\beta-I / L}$ are the molar enthalpy and molar volume differences between an empty hydrate lattice and ice or liquid water. $\Delta h_{w}^{\beta-I / L}$ is given by the following equation (Anderson and Prausnitz, 1986; Holder et al., 1980):

$$
\Delta h_{w}^{\beta-I / L}=\Delta h_{w}^{0}+\int_{T_{0}}^{T} \Delta C_{P_{w}}^{,} d T
$$

where $C^{\prime}$ and subscript $P$ refer to molar heat capacity and pressure, respectively. $\Delta h_{w}^{0}$ is the enthalpy difference between the empty hydrate lattice and pure water, at the triple point. The heat capacity difference between the empty hydrate lattice and the pure liquid water phase, $\Delta C_{P w}^{,}$is also temperature dependent and the equation recommended by Holder $e t$ al . (1980) is used:

$$
\Delta C_{P_{w}}=-37.32+0.179\left(T-T_{0}\right) \quad T>T_{0}
$$

where $\Delta C_{P w}^{\prime}$ is in $\mathrm{J} \mathrm{mol}^{-1} \mathrm{~K}^{-1}$. Furthermore, the heat capacity difference between hydrate structures and ice is set to zero. The reference properties used are summarized in Table 8.

TABLE 8

Thermodynamic reference properties for structure I hydrates in the ice/liquid water region

\begin{tabular}{c|c|c|c}
\hline $\begin{array}{c}\text { Reference } \\
\text { property }\end{array}$ & $\begin{array}{c}\text { Value in ice } \\
\text { region }\end{array}$ & $\begin{array}{c}\text { Value in liquid } \\
\text { water region }\end{array}$ & References \\
\hline$\Delta u_{w}^{\circ}\left(\mathrm{J} \mathrm{mol}^{-1}\right)$ & 1297 & 1297 & $\begin{array}{c}\text { Dharmawardhana } \\
\text { et al., 1980 }\end{array}$ \\
\hline$\Delta u_{w}^{\circ}\left(\mathrm{J} \mathrm{mol}^{-1}\right)$ & 1389 & -4620.5 & $\begin{array}{c}\text { Dharmawardhana } \\
\text { et al., 1980 }\end{array}$ \\
\hline$\Delta v_{w}\left(\mathrm{~cm}^{3} \mathrm{~mol}^{-1}\right)$ & 3.0 & 4.601 & $\begin{array}{c}\text { Parrish and } \\
\text { Prausnitz, 1972 }\end{array}$ \\
\hline
\end{tabular}

\subsection{Modeling the Capillary Effect on Hydrate Stability Condition}

To model the hydrate dissociation conditions in porous media, the approach introduced by Llamedo et al. (2004) has been used to take into account the effect of capillary pressure. To account for capillary pressure effects on phase fugacities, a correction similar to the Poynting correction for saturated liquids has been applied, with the assumption that the molar volumes of the hydrate and/or aqueous phases are unaffected by capillary pressures (Smith and Van Ness, 1987):

$$
f_{i}^{\text {cappillary }}=f_{i}^{\text {bulk }} \exp \left(\frac{v_{i} P_{e}}{R T}\right)
$$


where $v_{i}$ is the molar volume, $R$ is the gas constant and $T$ is the temperature in $\mathrm{K}$ and $P_{e}$ is the capillary pressure, given by:

$$
P_{e}=\frac{F \gamma_{h l} \cos \theta}{r}
$$

where $\gamma_{h l}$ the specific surface energy of hydrate-liquid interface, $F$ shaping factor for the interface and $\theta$ the contact angle between the solid and the pore wall.

The model assumes cylindrical pores, and the curvature of $1 / r$ ( $r$ is the nominal pore radius) has been considered for modeling the dissociation condition, in accordance with accepted capillary theory. The model assumes water to be the wetting phase on silica surface as observed by Tohidi et al. (2001) and that the porous media is saturated with the liquid phase. Within the pore space, clathrates are subjected to a higher pressure due to the capillary pressure effects, resulting in inhibition. For modeling purposes, the value for the liquidhydrate interfacial tension, the only parameter required for the modeling, was considered to be $0.032 \mathrm{~J} / \mathrm{m}^{2}$ and the shape factor equal to one as it is a function of curvature of hydrateliquid interface. More details about the modeling of gas hydrate growth and dissociation in narrow pores and capillary inhibition effect can be found elsewhere (Anderson et al., 2006; Llamedo et al., 2004).

\section{RESULTS AND DISCUSSIONS}

For binary systems containing a self-associating (water) and a non-associating compound (methane), the binary interaction parameters $k_{i j}$ are the only adjustable parameters and
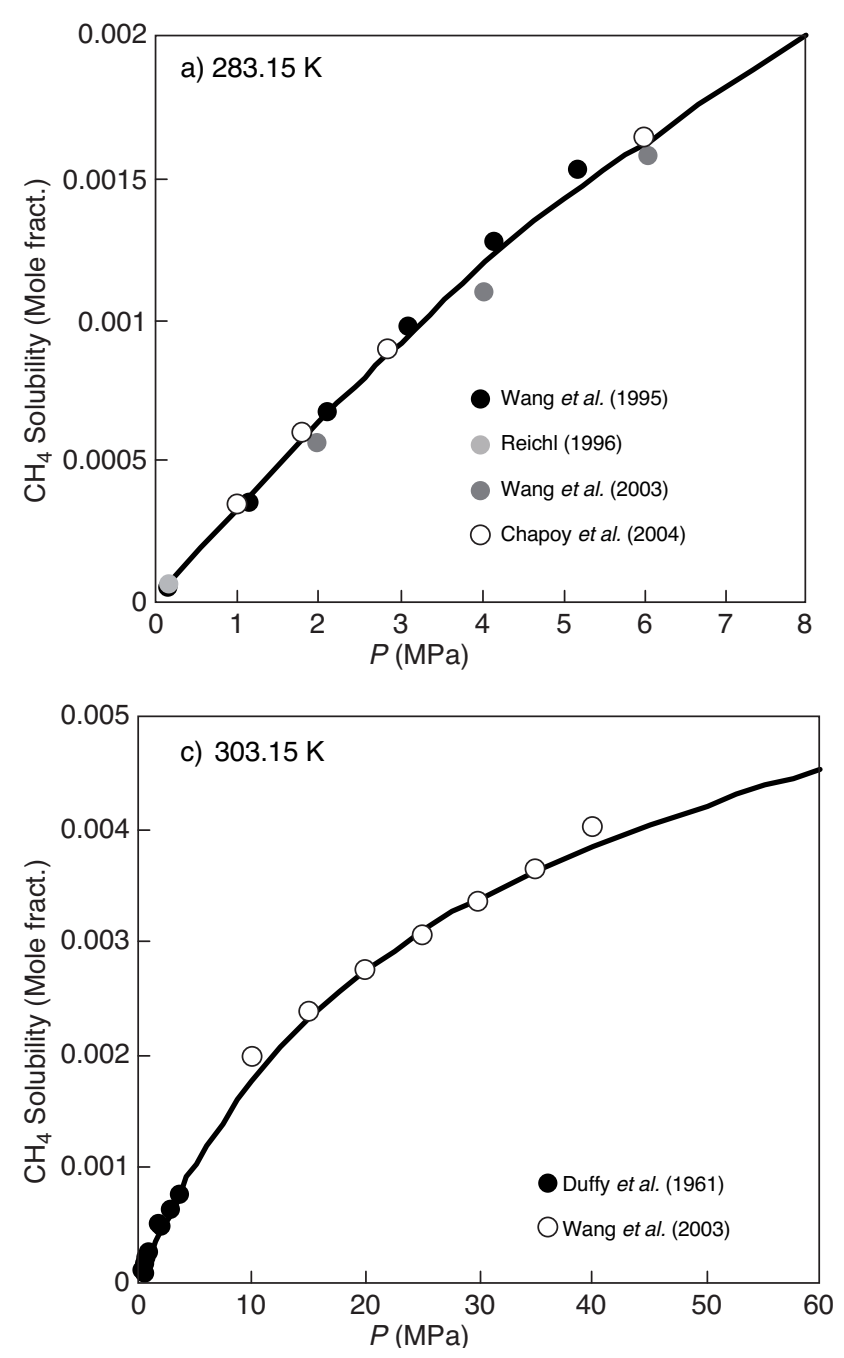

Figure 3

Solubility of methane in water.
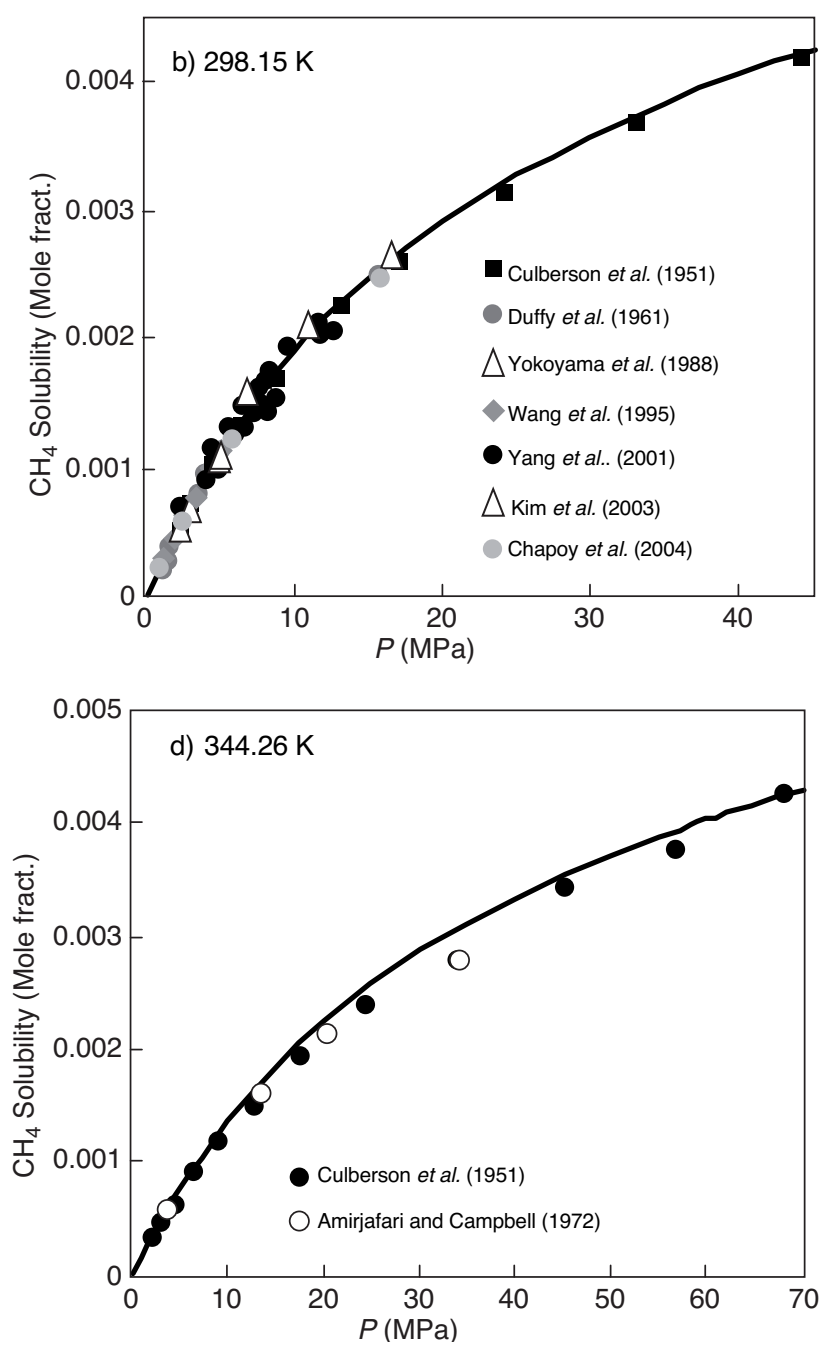
thus no combining rules are required for the associating energy and volume. Experimental water content data, at low temperatures, for hydrocarbons and non-hydrocarbon gases are scarce and often rather dispersed. This is partly due to the fact that the water content of gases is very low at low temperatures and high pressures and hence generally very difficult to measure, however, measuring gas solubility in water is easier than measuring the water content of gases. Due to this fact, the following objective function was employed for tuning the binary interaction parameter between methane and water:

$$
O F=\sum_{i}^{N P}\left(\frac{x_{i}^{\text {calc. }}-x_{i}^{\text {exp. }}}{x_{i}^{\text {exp. }}}\right)^{2}
$$

By minimizing the average absolute deviations in the solubility of methane in water in the range of $273.15 \mathrm{~K}$ up to $393.15 \mathrm{~K}$ (using the data from Chapoy et al., 2004; Culberson and Mc Ketta, 1951), a quadratic temperature dependent $k_{i j}$ has been established.

$$
k_{i j}=-1.18 \times 10^{-5} T^{2}+0.0102 T-1.9668
$$

After gathering the available data from the literature and tuning the binary interaction parameters for methane and water, experimental solubility data were used to evaluate the predictions of the model. Figure 3 and Figure 4 present the results of the CPA models for predicting the solubility of methane in water and the water content in the gas phase, respectively. The model predictions are in an excellent agreement with the experimental data, demonstrating the reliability of the developed model.

The next step was to evaluate the performance of the model in predicting the hydrate stability zone in the presence of electrolyte solutions. New experimental data for different concentrations of single salts measured in this work, in addition to the data from the literature, have been used for evaluating the model. As shown in Figure 5 to Figure 8 , the model can accurately predict the inhibition effect of salts on the hydrate stability conditions; good agreement with the data generated in this work is observed for both single and mixed electrolyte solutions. However, the published experimental data by Kang et al. (1998) for 15 mass\% of $\mathrm{MgCl}_{2}$ are consistently displaced to lower

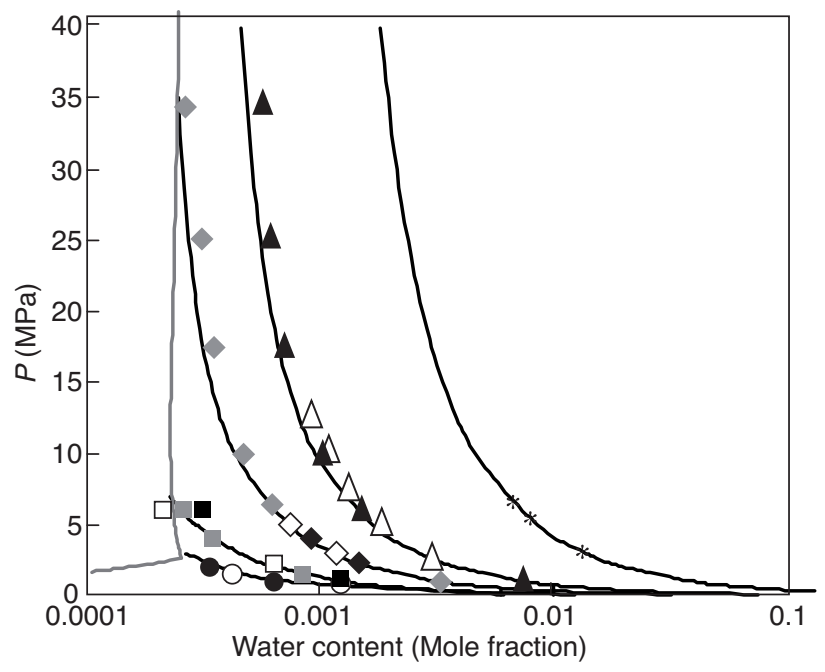

Figure 4

Water content of methane in equilibrium with liquid water. Experimental data at $273.11 \mathrm{~K}$ from Kosyakov et al., 1982 (O) and Althaus, $1999(\bigcirc)$. Experimental data at $283.1 \mathrm{~K}$

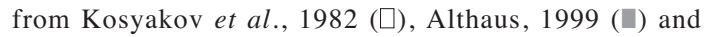
Chapoy et al. (2003) (অ). Experimental data at $298.1 \mathrm{~K}$ from Rigby and Prausnitz, 1968 ( ), Yokoyama et al., $1988(\diamond)$ and Chapoy et al., 2003 ( $\diamond)$. Experimental data at $313.13 \mathrm{~K}$ from Yarym-Agaev et al., $1985(\triangle)$ and Chapoy et al., 2003 (ム). Experimental data at $348.15 \mathrm{~K}$ from Rigby and Prausnitz, 1968 (*). Black lines are model predictions for the water content of methane. Gray line shows the methane hydrate phase boundary.

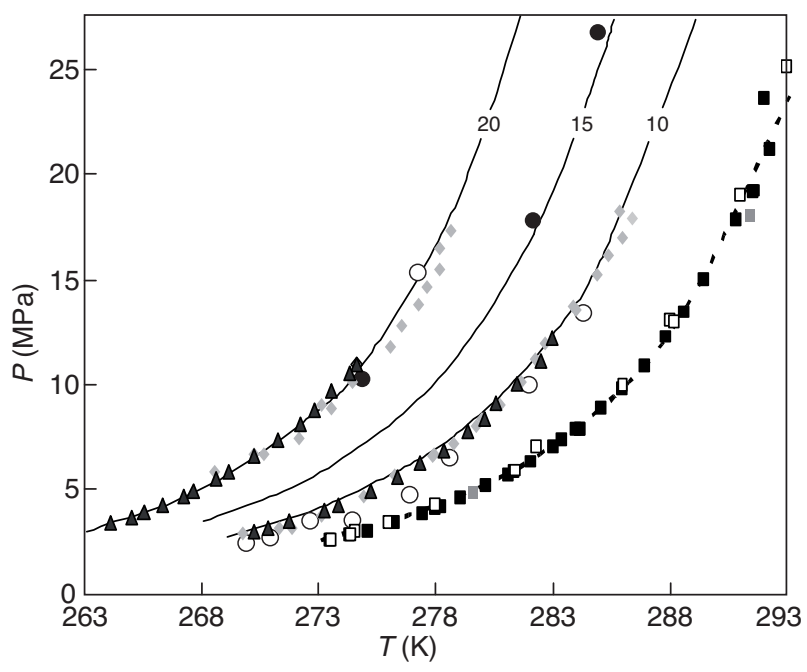

Figure 5

Methane hydrate dissociation conditions in the presence of $\mathrm{NaCl}$. Experimental data in presence of 10 mass\% of $\mathrm{NaCl}$ from: Kabayashi et al., 1951 (○), Maekawa et al., 1995 (४) and Maekawa and Imai, $1999(\mathbf{\Lambda})$. Experimental data in presence of 15 mass\% of $\mathrm{NaCl}$ from: this work (-). Experimental data in presence of 20 mass $\%$ of $\mathrm{NaCl}$ from: Maekawa et al., 1995 (४), Maekawa and Imai, 1999 (४) and this work. Experimental data for methane hydrate (distilled water) from: Blanc and Tournier-Lasserve, 1990 ( $\square$ ), Ross and Tocyzylkin, 1992 ( $\square$ ), and Nixdorf and Oellrich, 1997 (Ш). Black lines are the predicted methane hydrate phase boundary in presence of $\mathrm{NaCl}$. Dotted black line is the predicted methane hydrate phase boundary (distilled water). 


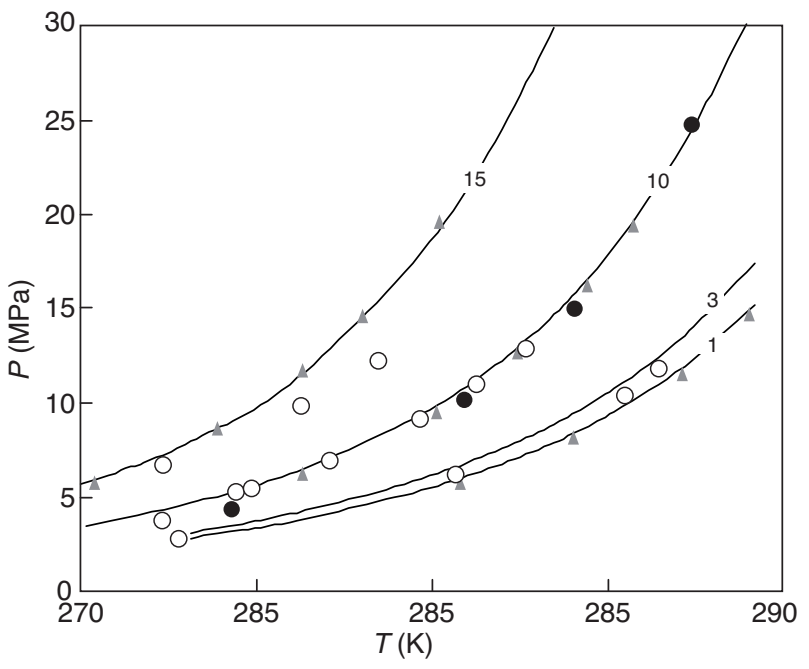

Figure 6

Methane hydrate dissociation conditions in the presence of $\mathrm{MgCl}_{2}$. Experimental data in presence of 1 mass\% of $\mathrm{MgCl}_{2}$ from: Atik et al., $2006(\Delta)$. Experimental data in presence of 3 mass\% of $\mathrm{MgCl}_{2}$ from: Kang et al., 1998 ( $\left.\bigcirc\right)$. Experimental data in presence of 10 mass $\%$ of $\mathrm{MgCl}_{2}$ from: Kang et al., 1998 (O), Atik et al., 2006 (॥) and this work (-) Experimental data in presence of 15 mass\% of $\mathrm{MgCl}_{2}$ from: Kang et al., $1998(0)$ and Atik et al., 2006 (\). Black lines are the predicted methane hydrate phase boundary in presence of $\mathrm{MgCl}_{2}$.

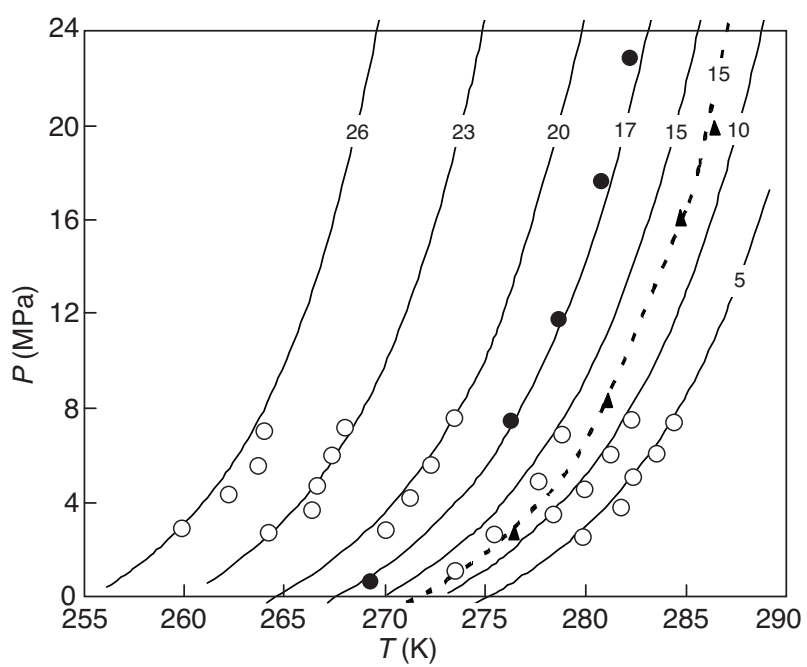

Figure 7

Methane hydrate dissociation conditions in the presence of $\mathrm{CaCl}_{2}$ or $\mathrm{KCl}$. Experimental data in presence of $5,10,15,20$, 23 and 26 mass\% of $\mathrm{CaCl}_{2}$ from: Kharrat and Dalmazzone, $2003(\bigcirc)$. Experimental data in presence of 17 mass \% of $\mathrm{MgCl}_{2}$ from: Atik et al., 2006 (๑). Experimental data in presence of $\mathrm{KCl}$ from: this work $(\boldsymbol{\Lambda})$. Black lines are the predicted methane hydrate phase boundary in presence of $\mathrm{MgCl}_{2}$. Dotted black line is the predicted methane hydrate phase boundary in presence of $\mathrm{KCl}$.

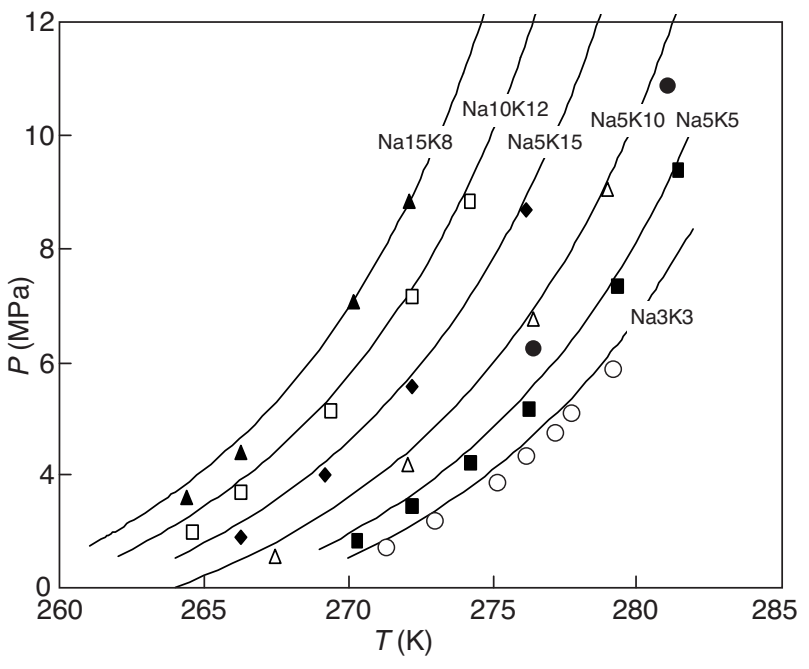

Figure 8

Methane hydrate dissociation conditions in the presence of mixture of $\mathrm{NaCl}$ and $\mathrm{KCl}$. Experimental data from: Dholabhai et al., 1991. Black lines are the predicted methane hydrate phase boundary in presence of the salt mixture.

pressures as compared to the data from Atik et al. (2006) and our own experimental data (see Fig. 6).

To evaluate the capability of the model for predicting methane hydrate dissociation conditions in porous media, the capillary inhibition effect on the stability of hydrate has been taken into account. The predictions of the model for different pore sizes have been validated against reliable independent experimental data generated in meso-porous silica media. The experimental data and the calculated hydrate dissociation conditions are presented in Figure 9, wherein the model predictions are seen to agree well with the experimental data. It should be noted that these data could be regarded as independent as hydrate dissociation data are not used in extending the thermodynamic model to porous media.

\section{CONCLUSIONS}

Reliable methane hydrate dissociation data in the presence of single electrolyte solutions containing 15 and 20 mass $\%$ $\mathrm{NaCl}, 15$ mass \% of $\mathrm{KCl}$ and 10 mass $\%$ of $\mathrm{MgCl}_{2}$ have been measured. These data in addition to the most reliable data from literature have been used to validate the predictive capabilities of a thermodynamic model developed in this work. In the developed thermodynamic model, the fugacity of each component in the salt free water phase has been calculated by the CPA EoS and the Debye Hückel electrostatic term was used for taking into the account the effect of salt on water/gas fugacity when electrolytes are present. The 


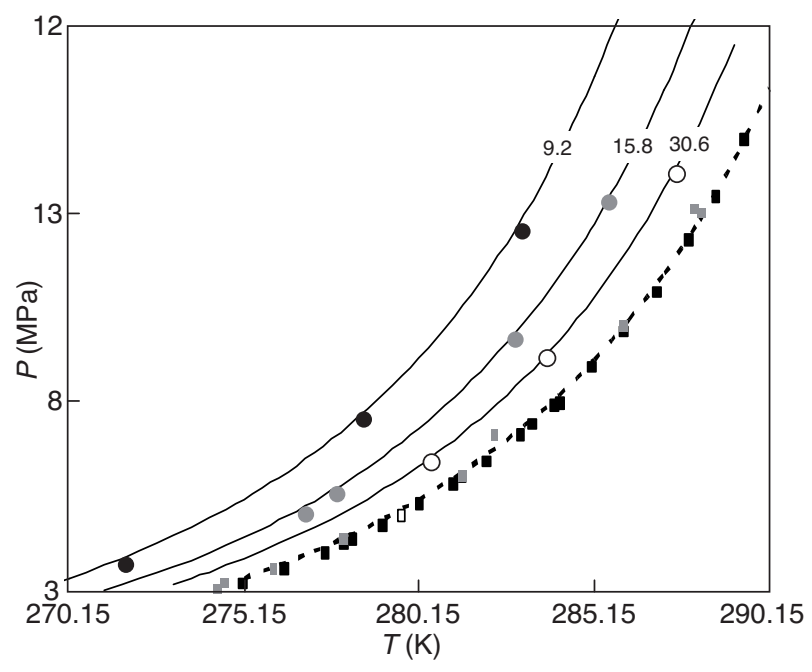

Figure 9

Methane hydrates dissociation conditions in meso-porous silica. Experimental data for methane hydrate in porous media from: Anderson et al., 2004, (•) $9.2 \mathrm{~nm}(\bullet) 15.8 \mathrm{~nm}$ and $(\bigcirc) 30.6 \mathrm{~nm}$. Experimental data for methane hydrate (distilled water) from: Blanc and Tournier-Lasserve, 1990

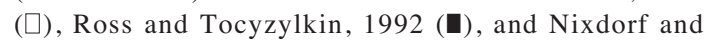
Oellrich, 1997 (凹). Black lines are the predicted methane hydrate phase boundary in porous media. Dotted black line is the predicted methane hydrate phase boundary (distilled water).

available experimental data for the solubility of methane in water were employed to optimize the binary interaction parameters between water and methane. Model predictions are validated against independent experimental data. Despite the wide range of temperature and salt concentrations the model was found to be very successful in predicting the phase behavior of water and methane in presence of electrolyte solutions. Good agreement between model predictions and independent experimental data for gas solubility in water and hydrate stability zone (in bulk and porous media) is observed, demonstrating the reliability and robustness of the developed model.

\section{ACKNOWLEDGEMENTS}

This work was funded by the UK Engineering and Physical Sciences Research Council (EPSRC Grant No. EP/D052556/1), whose support is gratefully acknowledged.

\section{REFERENCES}

Aasberg-Petersen K., Stenby E., Fredenslund A. (1991) Prediction of High-Pressure Gas Solubilities in Aqueous Mixtures of Electrolytes, Ind. Eng. Chem. Res. 30, 2180-2185.
Abdulgatov I.M., Bazaev A.R., Ramazanova A.E. (1993) Volumetric Properties and Virial Coefficients of (Water + Methane), J. Chem. Thermodyn. 25, 249-259.

Althaus K. (1999) Relationship Between Water Content and Water Dew Point Keeping in Consideration the Gas Composition in the Field of Natural Gas, Fortschr. Berichte VDI Reihe, 3, 350.

Amirijafari R., Campbell J. (1972) Solubility of Gaseous Hydrocarbon Mixtures in Water, Soc. Pet. Eng.J.21-27.

Anderson F.E., Prausnitz J.M. (1986) Inhibition of Gas Hydrates by Methanol, AIChE J.32, 8, 1321-1332.

Anderson R., Llamedo M., Tohidi B. (2004) Experimental Investigation of Methane Hydrate Growth and Dissociation Hysteresis in Narrow Pores, European Geosciences Union 1st General Assembly, France, April, pp. 25-30.

Anderson R., Tohidi B., Webber J.B.W. (2006) Gas Hydrate Growth and Dissociation in Narrow Pore Networks: Capillary Inhibition and Hysteresis Phenomena, Geological Society of London Conference on Sediment-hosted Gas Hydrates: New Insights on Natural and Synthetic Systems, UK, January, pp. 25-26.

Atik Z., Windmeier C., Oellrich L.R. (2006) Experimental Gas Hydrate Dissociation Pressures for Pure Methane in Aqueous Solutions of $\mathrm{MgCl}_{2}$ and $\mathrm{CaCl}_{2}$ and for a (Methane + Ethane) Gas Mixture in an Aqueous Solution of $\left(\mathrm{NaCl}+\mathrm{MgCl}_{2}\right)$, J. Chem. Eng. Data 51, 1862-1867.

Ben-Naim A., Yaacobi M. (1974) Effects of Solutes on the Strength of Hydrophobic Interaction and Its Temperature Dependence, $J$. Phys. Chem. 7, 2, 170-175.

Blanc C., Tournier-Lasserve J. (1990) Controlling Hydrates in High-Pressure Flow Lines, World Oil 211, 5, 63-68.

Blanco L.H., Smith N.O. (1978) High-Pressure Solubility of Methane in Aqueous Calcium-Chloride and Aqueous Tetraethylammonium Bromidepartial Molar Properties of Dissolved Methane and Nitrogen in Relation to Water-Structure, J. Phys. Chem. 8, 2, 186-191.

Blount C.W., Price L.C. (1982) Solubility of Methane in Water under Natural Conditions: A Laboratory Study. DOE Contract No. DE-A508- 78ET12145, Final Report.

Chapoy A., Coquelet C., Richon D. (2003) Solubility Measurement and Modeling of Water in the Gas Phase of the Methane/Water binary System at Temperatures from 283.15 to $318.15 \mathrm{~K}$ and Pressures up to $35 \mathrm{MPa}$, Fluid Phase Equilibr. 214, 101-107.

Chapoy A., Mohammadi A.H., Richon D., Tohidi B. (2004) Gas Solubility Measurement and Modeling for Methane - Water and Methane - Ethane - n-Butane - Water Systems Near Hydrate Forming Conditions, Fluid Phase Equilibr. 220, 113-121.

Cramer S.D. (1984) Solubility of Methane in Brines from 0Degrees-C to 300-Degrees-C, Ind. Eng. Chem. Process Des. Dev. 2 , 3, 533-538.

Crovetto R., Fernandez-Prini R., Japas M.L. (1982) Solubilities of Inert Gases and Methane in $\mathrm{H}_{2} \mathrm{O}$ and in $\mathrm{D}_{2} \mathrm{O}$ in the Temperature Range of 300 to 600 K, J. Chem. Phys. 76, 2, 1077-1086.

Culberson O.L., Horn A.B., Mc Ketta J.J. Jr (1950) Phase Equilibria in Hydrocarbon-Water Systems: The Solubility of Ethane in Water at Pressures up to 1200 Pounds per Square Inch, AIME 189, 1-6.

Culberson O.L., Mc Ketta J.J. Jr (1951) Phase Equilibria in Hydrocarbon-Water Systems III, The Solubility of Methane in Water at 10000 Psia, AIME 192, 223-226.

Davis J.E., Mc Ketta J.J. Jr (1960) Solubility of Methane in Water, Petrol.Refiner. 39, 205-206.

De Roo J.L., Peters C.I., Liechtenthaller R.N., Diepen G.A.M. (1983) Occurrence of Methane Hydrate in Saturated and Unsaturated Solution of Sodium Chloride and Water Independence of Temperature and Pressure, AIChE J. 29, 651-657. 
Dharmawardhana P.B., Parrish W.R., Sloan E.D. (1980) Experimental Thermodynamic Parameters for the Prediction of Natural Gas Hydrate Dissociation Conditions, Ind. Eng. Chem. Fundam. 19, 410-414.

Dholabhai P.D., Englezos P., Kalogerakis N., Bishnoi P.R. (1991) Equilibrium Conditions for Methane Hydrate Formation in Aqueous Mixed Electrolyte Solutions, Can.J. Chem. Eng. 69, 800-805.

Duffy J.R., Smith N.O., Nagy B. (1961) Solubility of Natural Gases in Aqueous Salt Solutions. 1. Liquidus Surfaces in the System $\mathrm{CH}_{4}-\mathrm{H}_{2} \mathrm{O}-\mathrm{NaCl}-\mathrm{CaCl}_{2}$ at Room Temperatures and at Pressures Below 1000 Psia, Geochim. Cosmochim. Ac. 2, 1-2, 23-31.

Eucken A., Hertzberg G. (1950) Aussalzeffekt und Ionenhydratation, Z. Phys. Chem. 195, 1-23.

Frolich K., Tauch E.J., Hogan J.J., Peer A.A. (1931) Solubility of Gases in Liquids at High Pressures, Ind. Eng. Chem. 23, 548-550.

Haghighi H., Chapoy A., Tohidi B. (2008) Freezing Point Depression of Electrolyte Solutions: Experimental Measurements and Modeling Using the CPA Equation of State, Ind. Eng. Chem. Res. (in press).

Hilderbrabd M. (1968) Solutions of Inert Gases in Water, J. Am. Chem. Soc. 90, 3001-3004.

Holder G.D., Corbin G., Papadopoulos K.D. (1980) Thermodynamic and Molecular Properties of Gas Hydrate from Mixtures Containing Methane, Argon and Krypton, Ind. Eng. Chem. Fundam. 19, 282-286.

Huang S.H., Radosz M. (1990) Equation of State for Small, Large, Polydisperse and Associating Molecules, Ind. Eng. Chem. Res. 29, 2284-2294.

Jager M.D., Sloan E.D. (2001) The Effect of Pressure on Methane Hydration in Pure Water and Sodium Chloride Solutions, Fluid Phase Equilibr. 185, 1-2, 89-99.

Kang S.P., Chun M.K., Lee H. (1998) Phase Equilibria of Methane and Carbon Dioxide Hydrates in the Aqueous $\mathrm{MgCl}_{2}$ Solutions, Fluid Phase Equilibr. 147, 229-238.

Kharrat M., Dalmazzone D. (2003) Experimental Determination of Stability Conditions of Methane Hydrate in Aqueous Calcium Chloride Solutions Using High Pressure Differential Scanning Calorimetry, J. Chem. Thermodyn. 35, 1489-1505.

Kiepe J., Horstmann S., Fischer K., Gmehling J. (2003) Experimental Determination and Prediction of Gas Solubility Data for Methane + Water Solutions Containing Different Monovalent Electrolytes, Ind. Eng. Chem. Res. 42, 5392-5398.

Kihara T. (1953) Virial Coefficient and Models of Molecules in Gases, Rev. Mod. Phys. 25, 4, 831-843.

Kim Y.S., Ryu S.K., Yang S.O., Lee C.S. (2003) Liquid WaterHydrate Equilibrium Measurements and Unified Predictions of Hydrate-Containing Phase Equilibria for Methane, Ethane, Propane, and Their Mixtures, Ind. Eng. Chem. Res. 42, 2409-2414.

Kobayashi R., Withrow H.J., Williams G.B., Katz D.L. (1951) Gas Hydrate Formation with Brine and Ethanol Solutions, Proceeding of the 30th Annual Convention, Natural Gasoline Association of America, USA, pp. 27-31.

Kontogeorgis G.M., Michelsen M.L., Folas G.K., Derawi S., von Solms N., Stenby E.H. (2006) Ten Years with the CPA (CubicPlus-Association) Equation of State. Part 1. Pure Compounds and Self-Associating Systems, Ind. Eng. Chem. Res. 45, 4855-4868.

Kontogeorgis G.M., Voutsas E.C., Yakoumis I.V., Tassios D.P. (1996) An Equation of State for Associating Fluids, Ind. Eng. Chem.Res. 35, 4310-4318.

Kontogeorgis G.M., Yakoumis I.V., Meijer H., Hendriks E.M., Moorwood T. (1999) Multicomponent Phase Equilibrium Calculations for Water-Methanol-Alkane Mixtures, Fluid Phase Equilibr. 158, 201-209.
Kosyakov N.E., Ivchenko B.I., Krishtopa P.P. (1982) Vopr. Khim. Tekhnol. 68, 33-36.

Krader T., Franck E.U. (1987) The Ternary Systems $\mathrm{H}_{2} \mathrm{O}-\mathrm{CH}_{4}-\mathrm{NaCl}$ and $\mathrm{H}_{2} \mathrm{O}-\mathrm{CH}_{4}-\mathrm{CaCl}_{2}$ to $800 \mathrm{~K}$ and 250 Bar, Ber. Bunsengers Phys. Chem. 91, 627-634.

Lekvam K., Bishnoi P.R. (1997) Dissolution of Methane in Water at Low Temperatures and Intermediate Pressures, Fluid Phase Equilibr. 131, 297-309.

Llamedo M., Anderson R., Tohidi B. (2004) Thermodynamic Prediction of Clathrate Hydrate Dissociation Conditions in Mesoporous Media, Am. Mineral. 89, 1264-1270.

Maekawa T., Itoh S., Sakata S., Igari S.I., Imai N. (1995) Pressure and Temperature Conditions for Methane Hydrate Dissociation in Sodium Chloride Solutions, Geochem. J. 29, 325-329.

Maekeawa T., Imai N. (1999) Equilibrium Conditions of Methane and Ethane Hydrates in Aqueous Electrolyte Solutions, The 3rd $I C G H$, USA, July.

Maharajh D.M., Walkley J. (1973) Thermodynamic Solubility: Properties of Gas Mixtures. Part 1.-Two Component Gas Mixtures in Water at $25^{\circ} \mathrm{C}, J$. Chem. Soc. Faraday T. 1, 842-848.

McAuliffe C. (1963) Solubility in Water of C1-C9 Hydrocarbons, Nature 200, 1092-1093.

Michels A., Gerver J., Bijl A. (1936) The Influence of Pressure on the Solubility of Gases, Physica III 3819-3822.

Mishnina T.A., Avdeeva O.I., Bozhovskaya T.K. (1962) The Solubility of Methane in $\mathrm{NaCl}$ Aqueous Solutions, Inf. Sb., Vses. Nauchn-Issled. Geol. Inst. 56, 137-145.

Morrison T.J., Billet F. (1952) The Salting-Out of Non-Electrolytes. Part II. The Effect of Variation in Non-Electrolyte, J. Chem. Soc. 3819-3822.

Namiot A.Y., Skripka V.G., Ashmyan K.D. (1979) Influence of Water Dissolved Salt Upon Methane Solubility Under the Temperatures 50 to 350-Degrees-C, Geokhimiya 1, 147-149.

Nixdorf J., Oellrich L.R. (1997) Experimental Determination of Hydrate Equilibrium Conditions for Pure Gases, Binary and Ternary Mixtures and Natural Gases, Fluid Phase Equilibr. 139, 325-333.

O'Sullivan T.D., Smith N.O. (1970) Solubility and Partial Molar Volume of Nitrogen and Methane in Water and in Aqueous Sodium Chloride from 50 to 125 degrees and 100 to $600 \mathrm{~atm}$, J. Phys. Chem. 74, 7, 1460-1466.

Parrish W.R., Prausnitz J.M. (1972) Dissociation Pressures of Gas Hydrates Formed by Gas Mixtures, Ind. Eng. Chem. Process Des. Dev. 11, 1, 26-35.

Pierotti R.A. (1965) Aqueous Solutions of Nonpolar Gases, J. Phys. Chem. 69, 281-288.

Price L.C. (1979) Aqueous Solubility of Methane at Elevated Pressures and Temperatures, Am. Assoc. Pet. Geo. Bull. 63, 15271533.

Reichl H. (1996) Ph.D. Thesis, Tech. Univ. Berlin.

Rigby M., Prausnitz J.M. (1968) Solubility of Water in Compressed Nitrogen, Argon and Methane, J. Phys. Chem. 72, 330-334.

Ross M.J., Toczylkine L.S. (1992) Hydrate Dissociation Pressures for Methane or Ethane in the Presence of Aqueous Solutions of Triethylene Glycol, J. Chem Eng. Data 37, 4, 488-491.

Sanchez M., De Meer F. (1978) Equilibrio Liquido-Vapor del Sistema Metano-Agua Para Altas Presiones Y Temperaturas Comprendidas Entre 150 Y $300^{\circ} \mathrm{C}$, An. Quim. 74, 1325-1328.

Servio P., Englezos P. (2002) Measurement of Dissolved Methane in Water in Equilibrium with Its Hydrate, J. Chem. Eng. Data 47, $87-90$.

Sloan E.D. (1998) Clathrate Hydrates of Natural Gases, Marcel Dekker Inc., New York. 
Smith J.M., Van Ness H.C. (1987) Introduction to Chemical Engineering Thermodynamics, McGraw-Hill, New York.

Song K.Y., Fneyrou G., Martin R., Lievois J., Kobayashi R. (1997) Solubility Measurements of Methane and Ethane in Water and Near Hydrate Conditions, Fluid Phase Equilibr. 128, 249-260.

Stoessell R.K., Byrne P.A. (1982) Salting-Out of Methane in Single-Salt Solutions at $25^{\circ} \mathrm{C}$ and Below 800 Psia, Geochim. Cosmochim. Ac. 46, 8, 1327-1332.

Sultanov R.G., Skripka V.G., Namiot A.Y. (1971) Rastvormost Metana V Vode Pri Novysjennykh Temperaturakh I Davlenijakh, Gaz.Prom. 16, 6-7.

Tohidi B., Anderson R., Clennell B., Burgass R.W., Biderkab A.B. (2001) Visual Observation of Gas Hydrate Formation and Dissociation in Glass Micromodels, Geology 29, 867-870.

Tohidi B., Burgass R.W., Danesh A., Todd A.C., Østergaard K.K. (2000) Improving the Accuracy of Gas Hydrate Dissociation Point Measurements, Ann. N.Y. Acad.Sci.912, 924-931.

Tohidi B., Danesh A., Todd A.C (1996) Gas Solubility and Hydrate Formation, Presented at the First MASTER Workshop, Belgium, September, pp. 18-20.

Tohidi-Kalorazi B. (1995) Gas Hydrate Equilibria in the Presence of Electrolyte Solutions, Ph.D. Thesis, Heriot-Watt University.

Tokunaga J., Kawai M. (1975) Solubilities of Methane in Methanol Water and Ethanol Water Solutions, J. Chem. Eng. Jpn 8, 326.

Van der Waals J.H., Platteeuw J.C. (1959) Clathrate Solutions, Adv. Chem. Phys. 2, 1-57.
Voutsas E.C., Boulougouris G.C., Economou I.G., Tassios D.P. (2000) Water/Hydrocarbon Phase Equilibria Using the Thermodynamic Perturbation Theory, Ind. Eng. Chem. Res. 39, 797-804.

Wang L.K., Chen G.J., Han G.H., Guo X.Q., Guo T.M. (2003) Experimental Study on the Solubility of Natural Gas Components in Water with or without Hydrate Inhibitor, Fluid Phase Equilibr. 207, 143-154.

Wang Y., Han B., Yan H., Liu R. (1995) Solubility of $\mathrm{CH}_{4}$ in the Mixed Solvent t-Butyl Alcohol and Water, Thermochim. Acta 253, 327-334.

Yang S.O., Cho S.H., Lee H., Lee C.S. (2001) Measurement and Prediction of Phase Equilibria for Methane + Water in Hydrate Forming Conditions, Fluid Phase Equilibr. 185, 53-63.

Yano T., Suetaka T., Umehara T., Horiuchi A. (1974) Solubilities of Methane, Ethylene, and Propane in Aqueous Electrolyte Solutions, Kagaku Kogaku 38, 320-323.

Yarym-Agaev N.L., Sinyavskaya R.P., Koliushko I.I., Levinton LY. (1985) Zh. Prikl. Khim. 58, 165-168.

Yokoyama C., Wakana S., Kaminishi G.I., Takahashi S. (1988) Vapor-Liquid Equilibria in the Methane-Diethylene Glycol-Water System at 298.15 and 323.15 K, J. Chem. Eng. Data 33, 274 -276.

Final manuscript received in August 2008 Published online in November 2008 or distributed for profit or commercial advantage and that copies bear this notice and the full citation on the first page. Copyrights for components of this work owned by others than IFP must be honored. Abstracting with credit is permitted. To copy otherwise, to republish, to post on servers, or to redistribute to lists, requires prior specific permission and/or a fee: Request permission from Documentation, Institut français du pétrole, fax. +33147527078 , or revueogst@ifp.fr. 